\title{
Prevalence and risk indicators of gingivitis and periodontitis in a Multi-Centre study in North Jordan: a cross sectional study
}

\author{
Khansa Taha Ababneh ${ }^{1 *}$, Zafer Mohammad Faisal Abu Hwaij ${ }^{1}$ and Yousef S Khader ${ }^{2}$
}

\begin{abstract}
Background: There are limited data about the epidemiology and risk factors/indicators of gingivitis, aggressive periodontitis (AgP) and chronic periodontitis (CP) in Jordan. The aim of this study was to assess the prevalence and risk indicators of gingivitis, AgP and CP.

Methods: A sample of 595 subjects was randomly selected from subjects escorting out-patients attending a Medical Center, a Dental Teaching Hospital, and 2 private dental clinics. The socio-demographic variables, oral hygiene habits, income, smoking and Body Mass Index (BMI) were recorded. Full mouth periodontal examination was performed, and radiographs were taken for sites with probing depth $>3 \mathrm{~mm}$.

Results: About 76\% had gingivitis, 2.2\% had AgP and 5.5\% had CP. Periodontitis was more frequent among males than females with a M: F ratio of 1.6:1 and the prevalence increased with age. Subjects who reported not using a tooth brush, smokers and subjects with BMI $>30 \mathrm{~kg} / \mathrm{m}^{2}$ had significantly higher prevalence of periodontitis. The risk for periodontitis was greater among subjects who reported positive family history and subjects with $\leq 12$ years of education.

Conclusions: This is the first study to report on the prevalence of gingivitis, CP and AgP in North Jordanian. Age, low education, low frequency of tooth brushing and family history were significantly associated with increased risk of periodontitis.
\end{abstract}

Keywords: Prevalence, Odds Ratio, Aggressive Periodontitis, Chronic Periodontitis, Gingivitis, Jordan

\section{Background}

Periodontitis is a group of inflammatory diseases affecting the supporting tissues of the tooth. The American Academy of Periodontology (AAP) has classified periodontitis into aggressive periodontitis (AgP), chronic periodontitis $(\mathrm{CP})$ and periodontitis as a manifestation of systemic diseases [1]. Both AgP and CP have a multifactorial etiology with dental plaque as the initiating factor [2]. However, the initiation and progression of periodontitis are influenced by other factors including microbiologic, social and behavioral, systemic and genetic factors [3].

\footnotetext{
* Correspondence: KTAbabneh@hotmail.com

${ }^{1}$ Periodontology, Department of Preventive Dentistry, Faculty of Dentistry,

Jordan University of Science and Technology, Irbid, Jordan

Full list of author information is available at the end of the article
}

The prevalence of periodontal diseases varies in different regions of the world according to the definition of periodontitis and study population, and there are indications that they may be more prevalent in developing than in developed countries $[4,5]$. The National Health and Nutrition Examination Survey III (NHANES III) conducted in the United States (USA) between 19881994 [6] has demonstrated that $50 \%$ of the adult population has gingival inflammation. A national survey in the US has estimated that $19.9 \%$ of subjects aged 30 years, and $7.3 \%$ of those aged 90 years had clinical attachment level (CAL) $\geq 5 \mathrm{~mm}$ and $7 \mathrm{~mm}$, respectively. A national survey in the United Kingdom estimated that $42 \%$ of 35 - 44 years old and 70\% of 55-64 years old had CAL > $3.5 \mathrm{~mm}$, indicating presence of periodontitis [7]. The prevalence of $\mathrm{AgP}$ in the US ranges between 0.6\% in Whites and 2.6\% in African-Americans [8]. The aims of
C Biomed Central

() 2012 Ababneh et al; licensee BioMed Central Ltd. This is an Open Access article distributed under the terms of the Creative Commons Attribution License (http://creativecommons.org/licenses/by/2.0), which permits unrestricted use, distribution, and reproduction in any medium, provided the original work is properly cited. 
this study are based on the fact that, to date, there is no information on the prevalence of these two diseases in Jordan and no controlled studies of the risk indicators of periodontitis in the country. Therefore, this is the first report on the prevalence of $\mathrm{AP}, \mathrm{CP}$ and gingivitis and the first controlled study on their risk indicators in the northern part of Jordan.

\section{Methods}

\section{Study Population}

This investigation was undertaken with the understanding and consent of each participating subject and has been conducted in full accordance with ethical principles of the World Medical Association Declaration of Helsinki http://www.wma.net/en/30publications/10policies/b3/index.html. This study was approved by the Ethical Committee in the Deanship of Scientific Research at JUST and informed consents were obtained from the participants and the parents of those under 18 years of age, prior to the commencement of the study. The study included a random sample of people escorting out-patients attending JUST Medical Health Center and escorts to dental patients attending the Dental Department in Princess Basma Teaching Hospital and two dental private clinics in Irbid; no dental or medical patients were included. Princess Basma Teaching Hospital is a Ministry of Health hospital. The Ministry of Health is the main provider of primary health care (PHC) services in Jordan [9]. The reason for recruiting this population was based on the observation that subjects who accompanied patients in these centers are a diverse group in terms of residency, age and socioeconomic status (SES). Previous published work on the prevalence of periodontal disease and obesity among adults in north Jordan has used the same methodology [10].

Jordan has a population of around 6 million people. Irbid is the second largest populated governorate in Jordan with a population of 700,000 . Although there are health centers and hospitals in the rural areas and in smaller cities in Irbid governorate, many people residing there frequently seek medical and dental treatment in Irbid city. Therefore, the sample of the study is believed to be representative of the population in the northern part of Jordan. The minimum sample size needed was calculated assuming that the prevalence of AgP is 4\% among people aged 25 years or more. At a confidence level of $95 \%$, power of $80 \%$, and margin error of $2 \%$, the minimum sample size was calculated as 481 subjects.

\section{Exclusion criteria}

Subjects with ongoing or previous orthodontic treatment, subjects under current or previous periodontal treatment, those under the age of 14 years, pregnant women, subjects with diabetes mellitus or any syndromes, patients attending the medical/dental centers for dental or medical treatment, and subjects with any known/diagnosed form of immunosuppression or immunosuppressive medication were excluded from the study.

\section{Interview and Clinical Examination}

A structured questionnaire was completed for each subject by one of 3 qualified dentists. It included information about sociodemographic factors, oral hygiene habits, frequency of dental visits, smoking and family history of periodontal diseases.

For each participant, full mouth periodontal examination was performed and recorded on a special examination form by one of the 3 examiners. These data included probing depth (PD), clinical attachment level (CAL), the gingival index (GI) of Löe and Silness,[11] and the plaque index (PI) of Silness and Löe [12]. Each tooth, except third molars, was examined by "walking" the periodontal probe around the whole circumference of the tooth. PD and CAL were measured at six sites per tooth (mesio-, mid-, and disto-buccal; mesio-, mid-, and disto-lingual/ palatal). Inter-rate variability between the three examiners in the average, PD, CAL and GI were examined using one way Anova. There was no significant difference in the GI, PD and CAL between the three rates. Furthermore, the three rates similarly diagnosed periodontal diseases (AgP, CP). Intra-oral radiographs were taken for any site with $\mathrm{PD}>3 \mathrm{~mm}$ (bitewing for posterior teeth and periapical radiographs for anterior teeth) to reach or confirm diagnosis. The body mass index (BMI) was calculated by the equation: Weight $\mathrm{kg} /$ length $\mathrm{m}^{2}$. The weight and length were self reported. The categorization of BMI was based on the WHO criteria that classify BMI $<25 \mathrm{~kg} / \mathrm{m}^{2}$ as "normal", BMI 25-29.9 kg/m ${ }^{2}$ as "overweight" and BMI $\geq 30 \mathrm{~kg} / \mathrm{m}^{2}$ as "obese".

\section{Diagnosis}

Periodontal health was defined as the complete absence of gingivitis and/or periodontitis at any site. Gingivitis was defined as the presence of signs of plaque-induced gingival inflammation in at least one site. Signs of gingival inflammation including redness, swelling and/or bleeding on probing, that were not attributable to any other cause. Subjects were classified as having gingivitis (only) if they did not demonstrate any sign of attachment loss, such as pockets, gingival recession and bone loss. In cases where the probing depth was greater than $3 \mathrm{~mm}$, radiographs (bitewing for the posterior and periapical for the anterior teeth) were taken to investigate the presence of bone loss and, therefore, to differentiate between pseudopockets and true pockets. Periodontitis was defined as the presence of CAL $>2 \mathrm{~mm}$ on more than one tooth. The presence of alveolar bone loss was used to confirm the diagnosis of periodontitis. To 
differentiate between $\mathrm{CP}$ and AgP, clinical findings including PD, CAL, severity and (to a lower extent) pattern of bone loss, were used as diagnostic criteria. When the presence of CAL $>2 \mathrm{~mm}$ in addition to alveolar bone loss around at least two teeth was observed, one of which was a first molar, or when attachment and bone loss were present around first molars and/or incisors relatively earlier in life (i.e. $<50$ years), especially where the characteristic arc-shaped $\operatorname{defect}(\mathrm{s})$ was/were observed, the case was diagnosed as AgP. Inconsistence between the amount of deposits and the amount of destruction, and the presence of family history further confirmed the diagnosis of AgP. On the other hand, CP was diagnosed when CAL $>2 \mathrm{~mm}$ and/or alveolar bone loss were observed in more than one tooth, usually (but not always) in older age groups, i.e. $>50$ years. Young individuals with slight attachment and bone loss, where the amount of deposits was consistent with the amount of destruction, were diagnosed as having $\mathrm{CP}$.

\section{Statistical Analysis}

Statistical analysis was conducted using the Statistical Package for Social Sciences (SPSS version 15, Chicago, Illinois). Categorical variables were described using frequencies and percentages and continuous variables were described using means and standard deviations. Chisquare test was used to compare between percentages. The extent and severity of periodontal disease were analyzed using the General Linear Model multivariate procedure (GLM-multivariate analyses model). Binary logistic regression was used to determine factors associated with periodontal disease. A p-value of $<0.05$ was considered statistically significant.

\section{Results}

Prevalence of Periodontal Diseases

Table 1 shows that overall, $75.8 \%$ of the study sample had gingivitis, 5.5\% had CP, 2.2\% had AgP and only 16\%

Table 1 Prevalence of Gingivitis, CP and AgP According to Age

\begin{tabular}{|c|c|c|c|c|c|}
\hline \multirow{2}{*}{$\begin{array}{c}\text { Age } \\
\text { (years) }\end{array}$} & \multicolumn{4}{|c|}{ Diagnosis (Number) } & \multirow[b]{2}{*}{ Total (\%) } \\
\hline & $\begin{array}{c}\text { Healthy } \\
\text { (\%) }\end{array}$ & $\begin{array}{l}\text { Gingivitis } \\
\text { (\%) }\end{array}$ & $\begin{array}{l}A g P \\
(\%)\end{array}$ & $C P(\%)$ & \\
\hline$<20$ & $18(20.0)$ & $72(80.0)$ & $0(0.0)$ & $0(0.0)$ & $90(15.1)$ \\
\hline $20-29$ & $66(21.3)$ & $237(76.5)$ & $6(1.9)$ & $1(0.3)$ & $\begin{array}{c}311 \\
(52.3)\end{array}$ \\
\hline $30-39$ & $6(6.1)$ & $85(86.7)$ & $5(5.51)$ & $2(2.0)$ & $98(16.5)$ \\
\hline $40-49$ & 7 (10.6) & $43(65.2)$ & $2(3.0)$ & $\begin{array}{c}14 \\
(21.2) \\
\end{array}$ & $66(11.1)$ \\
\hline$\geq 50$ & $0(0.0)$ & $14(46.7)$ & $0(0.0)$ & $\begin{array}{c}16 \\
(53.3)\end{array}$ & $30(5.01)$ \\
\hline Total & $97(16.3)$ & $451(75.8)$ & $13(2.2)$ & $33(5.5)$ & 595 \\
\hline
\end{tabular}

had clinically healthy periodontium. Most participants were 20-29 years old. Table 1 demonstrates that CP was not common among subjects aged $<40$ years $(2.3 \%)$. Above this age, the prevalence sharply increased to $21.2 \%$ in the group aged $40-49$ years, and to $53.3 \%$ in subjects $\geq 50$ years old. It was decided to sum AgP and $\mathrm{CP}$ together in one "periodontitis group" when studying risk indicators, because the number of AgP patients was too low for examining risk indicators.

\section{Participants' characteristics, smoking, oral hygiene habits and frequency of dental visits}

This study included 595 participants (236 males and 359 females) aged 14 to 67 years with a mean (SD) of 28 (10.1) years. Their sociodemographic and relevant characteristics appear in Table 2, which shows that the majority of participants were females, had a family income $\geq 400$ Jordanian Dinars (JOD), had $>12$ years of education, lived in urban areas, had a normal weight, attended dental clinics on emergency only, reported regular tooth brushing, were non-smokers and reported no family history of periodontal diseases.

\section{Risk Indicators of Periodontitis}

The distribution of gingivitis and periodontitis according to sociodemographic and relevant characteristics is shown in Table 2. Periodontitis was more prevalent among males than females with a ratio of 1.6:1. A higher prevalence of periodontitis (9.9\%) was noticed among subjects with a total family income $<400$ JOD than among subjects with a higher income ( $\geq 400$ JDs); the same applied to gingivitis. There was a significant difference in the prevalence of periodontitis according to income between periodontitis and healthy groups $(p=$ 0.0005), as well as between the gingivitis and healthy groups. The majority of subjects with $\leq 12$ years of education had gingivitis followed by periodontitis, whereas the majority of subjects with $>12$ years of education had gingivitis and only $3.2 \%$ had periodontitis. A higher prevalence of gingivitis and periodontitis was found among subjects from rural areas than among those from urban areas. There were no significant differences in the prevalence of gingivitis or periodontitis according to residency, when compared to the healthy group ( $p=$ 0.051). As for BMI, it appeared that a significant difference exists between gingivitis and periodontally-healthy individuals as only $4 \%$ of subjects with BMI $<25 \mathrm{~kg} / \mathrm{m}^{2}$ had periodontitis, whereas $20.4 \%$ with BMI $>30 \mathrm{~kg} / \mathrm{m}^{2}$ had periodontitis $(p=0.0005)$. Subjects who reported emergency dental visits had a higher prevalence of gingivitis $(80.7 \%)$ and periodontitis $(8.3 \%)$ than subjects who reported regular dental visits.

The lowest prevalence of gingivitis $(71 \%)$ and periodontitis (6.4\%) was noticed among subjects who reported 
Table 2 Risk Indicators of Gingivitis and Periodontitis

\begin{tabular}{|c|c|c|c|c|c|c|c|}
\hline \multicolumn{2}{|c|}{ Variables } & \multirow{2}{*}{$\begin{array}{c}\text { Healthy } \\
\mathrm{N}(\%)\end{array}$} & \multirow{2}{*}{$\begin{array}{c}\text { Gingivitis } \\
\mathrm{N}(\%)\end{array}$} & \multirow{2}{*}{$\begin{array}{c}\text { Periodontitis } \\
\mathrm{N}(\%)\end{array}$} & \multirow{2}{*}{$\begin{array}{c}\text { Total } \\
\mathrm{N}(\%)\end{array}$} & \multirow[t]{2}{*}{ p-value* } & \multirow[t]{2}{*}{$p$-value } \\
\hline & & & & & & & \\
\hline \multirow[t]{2}{*}{ Gender } & Male & $23(9.7)$ & $193(81.8)$ & $20(8.5)$ & $236(39.7)$ & & \\
\hline & Female & $74(20.7)$ & $258(72.1)$ & $26(7.3)$ & $359(60.3)$ & & \\
\hline \multirow[t]{2}{*}{ Income $(J O D)^{\ddagger}$} & $<400$ & $28(9.5)$ & $237(80.6)$ & $29(9.9)$ & $295(49.6)$ & $<0.0005$ & $<0.0005$ \\
\hline & $\geq 400$ & 69 (23.0) & 214 (71.3) & $17(5.7)$ & $300(50.4)$ & & \\
\hline \multirow[t]{2}{*}{ Education (Years) } & $\leq 12$ & $21(11.1)$ & $135(71.4)$ & $33(17.5)$ & $189(31.8)$ & 0.101 & $<0.0005$ \\
\hline & $>12$ & 76 (18.8) & $316(78.0)$ & $13(3.2)$ & $406(68.2)$ & & \\
\hline \multirow[t]{2}{*}{ Residency } & Urban & 65 (18.5) & $264(75)$ & $23(6.5)$ & $352(59.2)$ & 0.122 & 0.051 \\
\hline & Rural & $32(13.2)$ & 187 (77.3) & $23(9.5)$ & $243(40.8)$ & & \\
\hline \multirow[t]{3}{*}{ BMI $\left(\mathrm{Kg} / \mathrm{m}^{2}\right)^{\S}$} & $<25$ & $78(20.9)$ & $280(74.9)$ & $16(4.3)$ & $375(62.9)$ & 0.002 & $<0.0005$ \\
\hline & $25-29$ & $16(9.7)$ & $130(78.8)$ & 19 (11.5) & $165(27.8)$ & & \\
\hline & $\geq 30$ & $3(5.6)$ & $40(74.1)$ & $11(20.4)$ & $54(9.3)$ & & \\
\hline \multirow[t]{3}{*}{ Dental visits } & Regular & $28(29.5)$ & $60(63.2)$ & $7(7.4)$ & $95(16.0)$ & 0.0005 & 0.070 \\
\hline & On need & $40(17.0)$ & $178(75.5)$ & $17(7.2)$ & $236(39.7)$ & & \\
\hline & Emergency & $29(11.0)$ & $213(80.7)$ & $22(8.3)$ & $264(44.3)$ & & \\
\hline \multirow[t]{3}{*}{ Brushing } & No brushing & $1(1.7)$ & $53(91.0)$ & $4(6.9)$ & $58(9.7)$ & $<0.0005$ & $<0.0005$ \\
\hline & Irregular(< 1/day) & 17 (9.8) & 138 (79.3) & 19 (10.9) & $174(29.2)$ & & \\
\hline & Regular ( $\geq 2 /$ day) & 79 (21.8) & $260(71.0)$ & $23(6.4)$ & $363(61.1)$ & & \\
\hline \multirow[t]{3}{*}{ Smoking } & No & $88(18.3)$ & $357(74.4)$ & $35(7.3)$ & $481(81.1)$ & 0.018 & 0.027 \\
\hline & Past & $1(5.9)$ & $13(76.5)$ & $3(17.6)$ & $17(2.9)$ & & \\
\hline & Current & $7(7.4)$ & $80(84.2)$ & $8(8.4)$ & $95(16.0)$ & & \\
\hline \multirow[t]{2}{*}{ Family history } & Yes & $22(13.2)$ & $126(75.4)$ & 19 (11.4) & $167(28.2)$ & 0.304 & 0.024 \\
\hline & No & $74(17.5)$ & $323(76.2)$ & $27(6.4)$ & $425(71.8)$ & & \\
\hline
\end{tabular}

*Gingivitis vs. Healthy

${ }^{\dagger}$ Periodontitis vs. Healthy

₹ Jordanian Dinars

$\S$ Body Mass Index

regular toothbrushing. In subjects reporting no brushing, the prevalence of gingivitis and periodontitis was almost $91 \%$ and $7 \%$, respectively. The PI was stratified into 3 groups (PI $<1$; PI $=1-2$ and PI $>2$ ) (results not shown in table). Within the AgP group $69.2 \%$ of individuals had PI $1-2$ and $30.8 \%$ had PI $>2$. Among CP subjects only 1 subject (3\%) had PI $<1,72.7 \%$ had PI $1-2$ and $24.3 \%$ had PI $>2$. Among the gingivitis group $15.3 \%$ had PI $<1,61 \%$ had PI $1-2$ and $23.7 \%$ had PI $>2$. Within the healthy group $82.5 \%$ had PI $<1,16.5 \%$ had PI $1-2$ and only $1 \%$ had PI $>2$.

The prevalence of gingivitis was highest among current cigarette smokers $(84.2 \%)$, whereas the prevalence of periodontitis was highest (17.6\%) among past smokers, less among current smokers (8.4\%) and least among non-smokers (7.4\%). There was a significant difference in the prevalence of periodontitis with regard to cigarette smoking between subjects in the periodontitis and healthy groups $(p=0.027)$.

\section{Extent and Severity of Periodontal Diseases}

The PI, GI, PD and CAL means are shown in Table 3. This Table shows that the healthy group demonstrates the lowest values of all examined parameters, whereas the AgP group shows the highest values. In addition, this Table shows that although the PI means of AgP and CP are comparable, the PD and CAL means for the AgP group are higher.

Table 4 demonstrates that almost $30 \%$ of sites in periodontitis subjects aged $\geq 50$ years exhibited CAL $\geq 3$

Table 3 The PI, GI, PD and CAL Means of the Study Population

\begin{tabular}{lcccc}
\hline VARIABLE & PI & GI & PD & CAL \\
\hline & MEAN \pm SD & MEAN \pm SD & MEAN \pm SD & MEAN \pm SD \\
\hline Healthy & $0.37 \pm 0.45$ & $0.097 \pm 0.34$ & $1.86 \pm 0.33$ & $0.00 \pm 0.00$ \\
Aggressive periodontitis & $1.67 \pm 0.52$ & $1.96 \pm 0.38$ & $3.5 \pm 0.37$ & $1.7 \pm 1.2$ \\
Chronic periodontitis & $1.5 \pm 0.35$ & $1.6 \pm 0.44$ & $2.86 \pm 0.38$ & $1.16 \pm 1.1$ \\
Gingivitis & $1.34 \pm 0.54$ & $1.35 \pm 0.45$ & $2.26 \pm 0.4$ & $0.012 \pm 0.14$ \\
\hline
\end{tabular}


Table 4 Extent and Severity of Periodontitis and GI according to Age

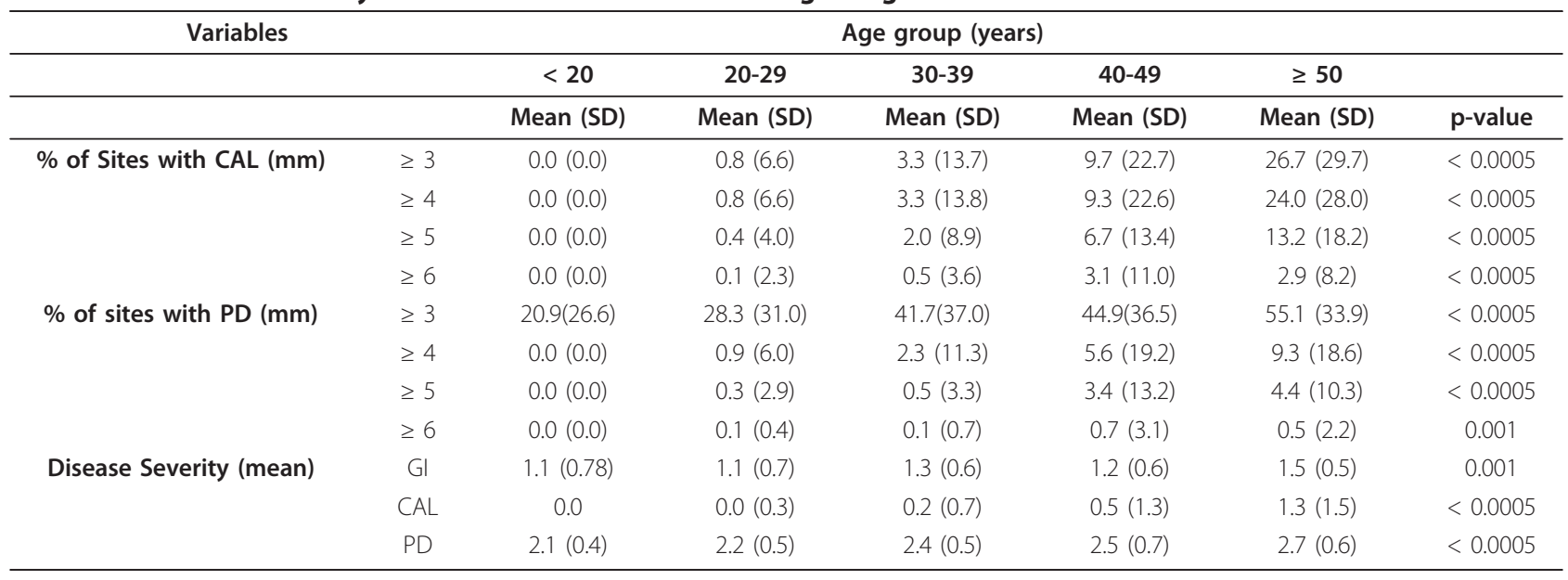

$\mathrm{mm}$ and this extent dropped to almost $7 \%$ in younger individuals (20-29 years). CAL $\geq 6 \mathrm{~mm}$ was present in $11 \%$ of sites among subjects aged 40-49 years and dropped to almost $8 \%$ of sites among subjects $\geq 50$ years old. The percentage of sites with $\mathrm{PD} \geq 3 \mathrm{~mm}$ was highest among subjects aged 40-49 years and the lowest percentage was observed among subjects $<20$ years old. As for disease severity, the highest mean GI, CAL and PD values were observed in the oldest age group $(\geq 50$ years).

\section{Multivariate Analysis}

In the multivariate analysis (Table 5), the only factors significantly associated with periodontitis were age, years of education, family history of periodontal diseases and frequency of tooth brushing. For each 1 year increase in age, the odds of having periodontitis increased by $20 \%$. Years of education $\leq 12$ years was associated with increased odds of having periodontitis by 5.5 times, compared to years of education $>12$. The odds of having periodontitis increased almost 25 times among

Table 5 Multivariate Analysis of Factors Associated with Periodontitis

\begin{tabular}{lcc}
\hline Variables & OR & P-value \\
\hline Age (years) & 1.2 & 0.000 \\
$\begin{array}{l}\text { Education (years) } \\
\quad 12\end{array}$ & 5.5 & 0.020 \\
$\quad>12$ & 1 & \\
Frequency of Tooth brushing & & 0.024 \\
$\quad$ No & 24.9 & \\
$\quad$ Irregular & 2.6 & \\
$\quad$ Regular & 1 & \\
Family History & & \\
$\quad$ Yes & & 0.033 \\
$\quad$ No & 4.8 & \\
\hline
\end{tabular}

subjects who reported not brushing their teeth compared to subjects who reported regular tooth brushing. Subjects who reported the presence of periodontal disease among other members of their families had almost 5 times higher odds of having periodontitis than subjects who reported negative family history.

\section{Discussion}

This is the first study reporting the prevalence and risk indicators of three periodontal diseases among adults in the northern part of Jordan. The prevalence of AgP was $2.2 \%$, of CP was $5.5 \%$ and of gingivitis was $75.8 \%$. The comparison of the current results with previous studies is hindered by the use of different nomenclature and diagnostic criteria across studies. The prevalence of CP was lower than expected, possibly because most participants were young and educated, or because of the strict exclusion criteria. The prevalence of AgP was within the range reported in the US for whites $(0.6 \%)$ and African Americans (2.8\%) [6]. A study on Jordanian adolescents reported that deep pockets were found in only $0.29 \%$ of the study sample [13]. A higher prevalence of AgP (6.0\%) has been recorded in Iraq [14] and in Brazil (5.5\%),[15] but a lower prevalence (1.7\%) was reported among Norwegian schoolchildren [14] than that obtained in the present study.

Most participants were 20-29 years old, probably reflecting the large proportion of young individuals in the Jordanian population or the possibility that most escorts were young. The lowest proportion of participants was $\geq 50$ years of age, probably because many older individuals were patients (not escorts) and were not recruited. All AgP subjects were under 30 years, which is not surprising as it is universally accepted that AgP starts early in life in susceptible individuals. Many authors believe that age is not a risk determinant, but the life time disease accumulation [16]. In the 
multivariate analysis, for each one year increase in age the odds of having periodontitis increased by $20 \%$ and most subjects with CP were above 40 years of age, in agreement with other studies [15,17].

Our results demonstrated that most gingivitis patients were males, which may be attributed to poor attitude towards health and smoking. As mentioned above, AgP and $\mathrm{CP}$ were summed together into one "periodontitis group" when studying risk indicators (except age), because the number of AgP patients was low. The male to female ratio of periodontitis (1.6:1) is in agreement with other studies $[18,19]$.

With regard to AgP, studies on Caucasians and Hispanics have demonstrated a greater female preponderance, [20] whereas studies involving Blacks demonstrated a greater prevalence in males. Albandar et al (2000) [19] reported a higher prevalence of AgP among females than males in Saudi Arabia with a ratio of 1.9:1. In a study in southern Brazil, AgP was distributed equally between males and females [21]. The reasons for these gender differences may be genetic factors, attitude toward oral health and dental-visit behavior [22].

The prevalence of gingivitis and periodontitis was higher in the low income than in the high income category, probably due to difficulty in affording dental treatment and oral hygiene aids. Difference in the prevalence of periodontitis according to SES was observed in other studies [23]. However, some studies have shown a weak association between SES and periodontitis after adjustment for oral hygiene and smoking [16,24].

In the present study, a low level of education was significantly associated with increased prevalence of periodontitis and the odds of having periodontitis increased by 5.5 times in subjects with $\leq 12$ years of education. A higher prevalence of periodontitis among subjects with low education has been reported in Thailand [23]. In the USA, Borrell et al (2006) [25] reported that subjects with $<$ high school education were 3 times more likely to have periodontitis than subjects with a higher level of education.

In the present study, subjects living in rural areas had a higher prevalence of gingivitis and periodontitis than subjects living in urban areas. Rural areas often have lower socioeconomic conditions and medical facilities than urban areas. Several studies have documented an association between area-based socioeconomic indicators and health outcomes [26]. Borrell et al (2006),[25] using data of the NHANES III, reported an association between periodontitis and neighborhood socioeconomic conditions.

A significantly higher prevalence of periodontitis was recorded among obese subjects than among normal weight subjects in the present study, which coincides with the results of the NHANES III in the USA [27].
Gingivitis was most prevalent among overweight subjects, although it was high in all BMI categories, with no clear pattern of association. A dose-dependent association between BMI and periodontitis was reported in Japan [28] after adjusting for age, sex, smoking and frequency of toothbrushing. Other studies [29] reported no significant difference in the prevalence of periodontitis between obese, overweight and normal subjects in males. Imbalance in the host immunity due to increased blood lipid and glucose levels in obese subjects may play a role in this association [30].

A higher prevalence of gingivitis and periodontitis was noticed among subjects who reported emergency dental visits, compared to subjects reporting regular dental visits, which is in agreement with reports in Brazil [21]. The lowest prevalence of gingivitis and periodontitis were observed among subjects reporting regular tooth brushing, whereas subjects reporting no tooth brushing had 25 times higher odds of having periodontitis. The effect of maintaining good oral hygiene on the periodontium is well documented [17,31]. In Accordance with this, our study demonstrated that most individuals with low PI $(<1)$ were periodontally healthy, whereas most people with gingivitis, $\mathrm{CP}$ and $\mathrm{AgP}$ had a high PI.

In this study, gingivitis was observed mostly in current smokers, probably indicating the strong and rapid effect of smoking on gingival health. The prevalence of periodontitis was also higher among smokers, in agreement with other studies [32]. Past smokers had a higher prevalence of periodontitis than current smokers; probably because the majority of past smokers were older in age and usually reported a long duration of smoking. Subjects who reported family history of periodontal disease had 5 times higher odds of having periodontitis than subjects with no family history. Positive family history of periodontal diseases has been reported previously $[33,34]$.

This study has demonstrated that when challenged with similar amounts of plaque, people with AgP suffer a greater amount of attachment loss, compared to subjects with $\mathrm{CP}$, indicating a higher susceptibility of the AgP group to periodontal destruction.

The greatest attachment loss and probing depth were present among older subjects ( $\geq 50$ years) and that the extent of periodontal destruction increased with increasing age, within all categories of disease severity (i.e. CAL categories), indicating cumulative periodontal destruction in susceptible individuals [16]. When addressing the different severities of periodontal destruction an interesting finding was observed; as from CAL $\geq 5 \mathrm{~mm}$ the extent of disease decreased, indicating that more sites were affected by moderate periodontitis than by severe periodontitis; teeth affected by severe periodontitis may have been lost. 


\section{Limitations to the work}

1. The main limitation of this study was unavailability of a portable $\mathrm{x}$-ray unit to the researchers. Numerous commercially available units exist, but almost all of them suffer serious safety shortages such as back scatter of the x-rays. They were evaluated by a specialist radiologist and the only "safe" portable $\mathrm{x}$-ray machine could not be obtained by the researchers, despite repetitive attempts. This dictated the choice of places where subjects could be recruited; i.e. clinics and centers where a dental $x$ ray unit was present. In future studies, a full portable examination unit should be obtained.

2. Many of the variables investigated depended on patients' reports such as oral hygiene habits, smoking and other. Subjects' reports may not be true or accurate sometimes.

\section{Strength of the Study}

The strength of the present study may be summarized in several points

1. The study sample was randomly selected from four centers in North Jordan; a large population in the Northern part of Jordan attend these centers.

2. Full clinical periodontal examination was performed for each subject.

3. Diagnosis of CP and AgP was based on, and strictly in accordance with, the criteria set by the AAP in 1999.

4. Diagnosis of periodontitis was confirmed radiographically using bitewing/periapical radiographs.

\section{Conclusions}

It is concluded that $75.8 \%$.of north Jordanians in this study had chronic gingivitis, 5.5\% had CP and 2.2\% had AgP. Age, education, frequency of tooth brushing and family history were significantly associated with increased risk for periodontitis. We recommend the onset of larger scale cross-sectional studies involving the whole country to investigate the prevalence of gingivitis and periodontitis. The risk indicators should be investigated in longitudinal studies to elucidate whether they are true risk factors.

\begin{abstract}
Acknowledgements and Funding
This investigation was supported by a grant from the Deanship of Scientific Research at Jordan University of Science and Technology (JUST). The authors wish to thank Jordan University of Science and Technology (JUST) for financially supporting the present study. Thanks are also due to JUST Dental Teaching Centre, JUST Medical centre, Princess Basmah Teaching Hospital and two private dental clinics for providing the venues and necessary equipment for participants' examination. Special thanks are due to Dr Malak Labbad and Dr Rawan Shehab for participating in data collection.
\end{abstract}

\section{Author details}

'Periodontology, Department of Preventive Dentistry, Faculty of Dentistry, Jordan University of Science and Technology, Irbid, Jordan. ${ }^{2}$ Community
Medicine \& Public Health, Faculty of Medicine, Jordan University of science and Technology, Irbid, Jordan.

\section{Authors' contributions}

KA participated in the research design, generally supervised the work and wrote the manuscript. ZA carried out participant interview and examination, participated in data analysis and in writing the manuscript. YK put the research design, generally supervised the work and carried out all statistical analysis. All authors have read and approved the final manuscript.

\section{Competing interests}

The authors declare that they have no competing interests.

Received: 12 April 2011 Accepted: 3 January 2012

Published: 3 January 2012

\section{References}

1. Armitage GC: Development of a classification system for periodontal disease and conditions. Ann Periodontol 1999, 4:1-6.

2. Page RC, Offenbacher S, Schroeder HE, Seymour GJ, Kornman KS: Advances in the pathogenesis of periodontitis: summary of developments, clinical implications and future directions. Periodontol 2000 1997, 14:216-48.

3. Brown LF, Beck JD, Rozier RG: Incidence of attachment loss in community-dwelling older adults. J Periodontol 1994, 65:316-23.

4. Baelum V, Fejerskov $O$, Karring $T$ : Oral hygiene, gingivitis and periodontal breakdown in adult Tanzanians. J Periodontal Res 1986, 21:221-32.

5. Stoltenberg JL, Osborn JB, Pihlström BL, Hardie NA, Aeppli DM, Huso BA, Bakdash MB, Fischer GE: Prevalence of periodontal disease in a health maintenance organization and comparisons to the national survey of oral health. J Periodontol 1993, 64:853-8.

6. Albandar JM, Kingman A: Gingival recession, gingival bleeding, and dental calculus in adults 30 years of age and older in the United States, 1988-1994. J Periodontol 1999, 70:30-43.

7. Morris AJ, Steele J, White DA: The oral cleanliness and periodontal health of UK adults in 1998. Br Dent J 2001, 191:186-92.

8. Albandar JM, Brown LJ, Brunelle JA, Löe H: Gingival state and dental calculus in early-onset periodontitis. J Periodontol 1996, 67:953-9.

9. Haddad LG, Shotar A, Younger JB, Alzyoud S, Bouhaidar CM: Screening for domestic violence in Jordan: validation of an Arabic version of a domestic violence against women questionnaire. Int J Women's Health 2011, 3:79-86.

10. Khader YS, Bawadi HA, Haroun TF, Alomari M, Tayyem RF: The association between periodontal disease and obesity among young adults in Jordan. J Clin Periodontol 2009, 36(1):18-24.

11. Löe $H$, Silness J: Periodontal disease in pregnancy. I. prevalence and severity. Acta Odontol Scand 1963, 21:533-51.

12. Silness J, Löe H: Periodontal disease in pregnancy. II. Correlation between oral hygiene and periodontal condition. Acta Odontol Scand 1964, 22:121-35.

13. Taani $\mathrm{Q}$ : The periodontal status of Jordanian adolescents measured by CPITN. Int Dent J 1995, 45(6):382-5.

14. Albandar JM: Prevalence of incipient radiographic periodontal lesions in relation to ethnic background and dental care provisions in young adults. J Clin Periodontol 1989, 16:625-9.

15. Susin C, Oppermann RV, Haugejorden O, Albandar JM: Tooth loss and associated risk indicators in an adult urban population from south Brazil. Acta Odontol Scand 2005, 63:85-93.

16. Genco RJ: Current view of risk factors for periodontal diseases. J Periodontol 1996, 67:1041-9.

17. Khader YS, Rice JC, Lefante JJ: Factors associated with periodontal diseases in a dental teaching clinic population in northern Jordan. $J$ Periodontol 2003, 74:1610-7.

18. Susin C, Dalla Vecchia CF, Oppermann RV, Haugejorden O, Albandar JM: Periodontal attachment loss in an urban population of Brazilian adults: effect of demographic, behavioral, and environmental risk indicators. J Periodontol 2004, 75:1033-41.

19. Albandar JM: Periodontal disease in North America. Periodontology 2000 2002, 29:31-69.

20. Baer PN: The case for periodontosis as a clinical entity. J Periodontol 1971, 42:516-20. 
21. Susin C, Albandar JM: Aggressive periodontitis in an urban population in southern Brazil. J Periodontol 2005, 76:468-75.

22. Nunn M: Understanding the etiology of periodontitis: an overview of periodontal risk factors. Periodontol 2000 2003, 32:11-23.

23. Torrungruang K, Tamsailom S, Rojanasomsith K, Sutdhibhisal S, Nisapakultorn $K$, Vanichjakvong O, Prapakamol S, Premsirinirund T, Pusiri T, Jaratkulangkoon O, Unkurapinun N, Sritara P: Risk indicators of periodontal disease in older Thai adults. J Periodontol 2005, 76:558-65.

24. Teng HC, Lee $C H$, Hung HC, Tsai CC, Chang YY, Yang YH, Lu CT, Yen YY, Wu YM: Lifestyle and psychosocial factors associated with chronic periodontitis in Taiwanese adults. J Periodontol 2003, 74:1169-75.

25. Borrell LN, Burt BA, Warren RC, Neighbors HW: The role of individual and neighborhood social factors on periodontitis: the third National Health and Nutrition Examination Survey. J Periodontol 2006, 77:444-53.

26. Diez Roux AV, Merkin SS, Arnett D, Chambless L, Massing M, Nieto FJ, Sorlie P, Szklo M, Tyroler HA, Watson RL: Neighborhood of residence and incidence of coronary heart disease. N Engl J Med 2001, 345:99-106.

27. Al-Zahrani MS, Bissada NF, Borawskit EA: Obesity and periodontal disease in young, middle-aged, and older adults. J Periodontol 2003, 74:610-5.

28. Nishida N, Tanaka M, Hayashi N, Nagata H, Takeshita T, Nakayama K, Morimoto K, Shizukuishi S: Determination of smoking and obesity as periodontitis risks using the classification and regression tree method. J Periodontol 2005, 76:923-8.

29. Dalla Vecchia CF, Susin C, Rösing CK, Oppermann RV, Albandar JM: Overweight and obesity as risk indicators for periodontitis in adults. $J$ Periodontol 2005, 76:1721-8.

30. Lamas O, Marti A, Martínez JA: Obesity and immunocompetence. Eur J Clin Nutr 2002, 56(Suppl 3):S42-5.

31. Axelsson $P$, Nyström $B$, Lindhe J: The long-term effect of a plaque control program on tooth mortality, caries and periodontal disease in adults. Results after 30 years of maintenance. $J$ Clin Periodontol 2004, 31:749-57.

32. Haffajee AD, Socransky SS: Relationship of cigarette smoking to attachment level profiles. J Clin Periodontol 2001, 28:283-95.

33. Boughman JA, Astemborski JA, Suzuki JB: Phenotypic assessment of early onset periodontitis in sibships. J Clin Periodontol 1992, 19:233-9.

34. Petit MD, van Steenbergen TJ, Timmerman MF, de Graaff J, van der Velden U: Prevalence of periodontitis and suspected periodontal pathogens in families of adult periodontitis patients. J Clin Periodontol 1994, 21:76-85.

\section{Pre-publication history}

The pre-publication history for this paper can be accessed here: http://www.biomedcentral.com/1472-6831/12/1/prepub

doi:10.1186/1472-6831-12-1

Cite this article as: Ababneh et al:: Prevalence and risk indicators of gingivitis and periodontitis in a Multi-Centre study in North Jordan: a cross sectional study. BMC Oral Health 2012 12:1.

\section{Submit your next manuscript to BioMed Central and take full advantage of:}

- Convenient online submission

- Thorough peer review

- No space constraints or color figure charges

- Immediate publication on acceptance

- Inclusion in PubMed, CAS, Scopus and Google Scholar

- Research which is freely available for redistribution

Submit your manuscript at www.biomedcentral.com/submit
Biomed Central 